\title{
WHERE ARE THE ELECTRIC VEHICLES? A SPATIAL MODEL FOR VEHICLE-CHOICE COUNT DATA
}

The following paper is a pre-print, the final publication can be found in the Journal of Transport Geography, 43: 181-188, 2015.

\author{
Kara M. Kockelman \\ (Corresponding author) \\ Professor and William J. Murray Jr. Fellow \\ Department of Civil, Architectural and Environmental Engineering \\ The University of Texas at Austin \\ kkockelm@mail.utexas.edu \\ Phone: 512-471-0210
}

\begin{abstract}
Electric vehicles (EVs) are predicted to increase in market share as auto manufacturers introduce more fuel efficient vehicles to meet stricter CAFE standards and driver concerns of increasing fuel costs. Reflecting spatial autocorrelation while controlling for a variety of demographic and locational (e.g., built environment) attributes, this zone-level spatial count model in this paper offers valuable information for power providers and charging station location decisions. By anticipating over 745,000 personal-vehicle registrations across a sample of 1000 census block groups in the Philadelphia region, a trivariate Poisson-lognormal conditional autoregressive (CAR) model anticipates Prius hybrid EV, other EV, and conventional vehicle ownership levels. Initial results signal higher EV ownership rates in more central zones with higher household incomes, along with significant residual spatial autocorrelation, suggesting that spatially-correlated latent variables and/or peer (neighbor) effects on purchase decisions are present. Such data sets will become more comprehensive and informative as EV market shares rise. This work's multivarate Poisson-lognormal CAR modeling approach offers a rigorous, behaviorally-defensible framework for spatial patterns in choice behavior.
\end{abstract}


KEY WORDS: Electric vehicles, spatial count modeling, vehicle choice, vehicle ownership, consumer behavior, conditional auto-regressive, built environment

\section{MOTIVATION}

As auto manufacturers introduce a variety of new vehicles to meet stricter fuel economy standards, in the U.S. and abroad, and driver concerns regarding long-term energy prices remain high, hybrid electric vehicle (HEV), plug-in hybrid electric vehicle (PHEV), and battery electric vehicle (BEV) sales are on the rise (Schweinberg 2013). After tracking the electric vehicle (EV) market for 13 years, IDTechEX predicts that $35 \%$ of all vehicles in the world will be electric by 2025, with a likely mix of 25\% hybrids and 10\% BEVs (Harrop and Das 2012). With such meaningful market share changes on the horizon, an ability to predict which households or neighborhoods are most likely to own such vehicles can provide important insights and opportunities for power-grid planning (e.g., updating transformers in certain locations), transportation investments (e.g., identifying where public charging stations should be installed for maximum utilization), and air quality policy-making (e.g., forecasting ozone level changes when more vehicle-miles are electrified).

Spatial patterns in growing EV ownership may also illuminate what causes or alleviates owner/consumer "range anxiety" (i.e., a user's concern for being stranded with a fully discharged battery and no reasonable recharge option [Tate et al. 2008]). As illustrated by Khan and Kockelman (2012), a 75-mile all-electric range (AER) BEV (like the 2013 Nissan LEAF) may be a very reasonable vehicle for $27 \%$ of single-vehicle households and nearly $70 \%$ of multiplevehicle households in Seattle to own, assuming existing travel patterns, a willingness to charge the vehicle once a day, and a willingness to charge more than once or find another travel option (e.g., a relative's car or rental vehicle) just 3 days a year, on average (in order to exceed the BEV's AER).

Recent evidence from the U.S. Department of Energy's and ECOtality's EV Project (Smart et al. 2013) suggests that $73 \%$ of miles driven by Americans in a Chevy Volt stay within its 35-mile (EPA-rated) AER (thereby avoiding much gasoline use in this PHEV). However, according to Consumer Reports' Car Brand Perception Survey (Bartlett 2012), range anxiety remains consumers' top concern consumer regarding a possible EV purchase. Studies suggest that such anxiety may fall as drivers become more familiar with EV technology and EV use (see, for example, Wellings et al. [2011] and Taylor [2009]). As with open-road tolling, adaptive cruise control, and other relatively new transport policies and technologies, it seems very possible that potential owners will worry less about EV range limitations as they are exposed to EVs on local roads, in neighbors' driveways, and nearby parking garages (Mau et al. 2008). Related to this, Axsen et al. (2009) surveyed over 1000 vehicle owners in Canada and California and found that willingness-to-pay (WTP) for HEVs rose with higher (existing)) HEV market penetration rates. This study econometrically models ownership rates of EVs and conventional vehicles across Philadelphia neighborhoods, while allowing for such neighbor (spatial autocorrelation) effects; it applies a new multivariate count model, with both spatially-lagged and (aspatial) cross-response correlation opportunities.

\section{BACKGROUND}


Most EV forecasts are simply an aggregate market share, across a nation or region, with estimates widely varying. For example, the U.S. National Research Council (2010) predicted 13 million EVs on U.S. roads by 2030 (4\% of total fleet) in the most probable scenario and 40 million EVs (13.3\% of total fleet) in the maximum practical case, while the U.S. Energy Information Administration (EIA 2013) recently forecasted just 3\% of all U.S. light duty vehicle (LDV) sales will be EVs by 2040. Simulating consumer behavior under a business-as-usual (BAU) model, Clement-Nyns et al. (2010) projected EVs to reach $30 \%$ of the Belgian passengervehicle fleet by 2030. McKinsey's (2011) survey suggested that in three of the world's "megacities" (New York City, Shanghai, and Paris), EVs may hit 16\% of vehicle sales by 2015. Within the U.S. northeast corridor, Pike Research (2011) projects that Washington, D.C. and Delaware will have the highest annualized penetration rates of EVs by 2017, at 4.6 and 4.5 percent, respectively. Paul et al.'s (2011) microsimulation of U.S. household holdings forecasted $7.6 \%$ of the fleet to be HEVs and PHEVs by 2035 under BAU, and $13.1 \%$ under a feebate plus doubled-gas price scenario, ceteris paribus. Examining both demand (for vehicles, batteries, and gasoline) and supply constraints (on production), Neubauer et al. (2012) projected California's PHEV + BEV population to hit 500,000 sometime between 2018 and 2020.

17 Many researchers have employed discrete choice models at a disaggregate (individual or household) level to explore various vehicle ownership decisions. For example, Brownstone et al. (1996) analyzed data from a stated preference survey on alternative-fuel vehicles and found that two-vehicle households with children express a greater WTP for cleaner (emissions-reducing) vehicles, as compared to childless households. Erdem et al. (2010) employed an ordered probit (OP) model to examine Turkish consumers' WTP for HEVs and found that higher-income females, with more education and concerns about global warming, are more likely to purchase HEVs. The relationship between income and vehicle preference tends to be complicated by household size: Paul et al. (2011) found that households with higher household income per member tend to prefer smaller vehicles, but larger households generally prefer larger vehicles (for seating-capacity reasons).

28 Land use characteristics also influence ownership decisions. For example, higher residential densities are associated with lower vehicle ownership and usage levels (e.g., Zhao and Kockelman [2002] and Fang [2008]). Holding other household attributes (control variables) constant, Brownstone and Golob (2009) predicted density reductions of 1,000 housing units per square mile (or 1.56 units per acre) to associated with another 1,000 miles per year of vehiclemiles traveled and 65 more gallons of fuel consumed per household (with 20 gallons of this difference accounted by choice of more fuel-efficient vehicles in higher-density settings). The choice of higher fuel-economy vehicles may be largely attributable to lower light-duty truck ${ }^{1}$ (LDT) ownership in such settings: Brownstone and Fang's (2009) Bayesian multivariate OP model associates a 50 percent residential density increase with a modest but statistically significant reduction on LDT ownership levels, and a 610-mile annual per-truck VMT decrease. In the same study, demand for passenger car ownership was estimated to be inelastic with respect to residential density (Brownstone and Fang 2009), but fuel economy can change significantly within the car fleet, leading to EV purchases, rather than say large, luxury cars, and thereby offer substantial energy savings. Using a multiple discrete-continuous extreme value (MCDEV)

\footnotetext{
${ }^{1}$ In the U.S. the light-duty truck definition includes cargo vans, minivans, sport-utility vehicles, and pickup trucks weighing less than 8,500 lbs loaded (i.e., the gross vehicle weight rating).
} 
specification, Bhat et al. (2009) also found that smaller vehicle sizes are more prevalent in neighborhoods high in both residential and commercial densities. Beyond simple density measures, Potoglou et al. (2008) found vehicle ownership to depend somewhat on land use diversity and transit proximity. Khan et al. (2012) also investigated the linkage between vehicle ownership and a host of built environment factors, including network structure, bus stop density, land use mix and jobs density, using a standard negative binomial model.

This research addresses a gap in our current understanding of EV ownership decisions by examining the effects of demographic and land use characteristics at the neighborhood (i.e., Census block group) level, rather than at a regional level or individual/household level. In this way, the work is able to quantify spatial autocorrelation or "neighbor effects" that can emerge in the adoption of new technologies, and to predict adoption rates over space, without requiring details on individuals.

\section{DATA DESCRIPTION}

The analysis relies on April 2012 vehicle registration data collected for the southeastern region of Pennsylvania, around Philadelphia, by the Delaware Valley Regional Planning Commission (DVRPC). The data set covers 2,980 census block groups containing 2,225,595 personal-vehicle registrations. 18,674 of these registered vehicles are considered EVs, and most of those (i.e.,

The response variables used in this paper's trivariate model are the number of Prius EVs, nonPrius EVs, and conventional (internal combustion engine) vehicles (ICEVs) in each Census block group. Predictor variables (i.e., covariates) include block-group demographics, such as population, resident worker ${ }^{2}$, and job densities, plus household income shares (by income range), and built-environment attributes (including distance to the central business district or CBD [downtown Philadelphia] and centerline-mile densities of primary and secondary roads), as discussed below.

The demographic details were originally provided at the traffic analysis zone (TAZ) level, by the regional MPO, DVRPC. TransCAD's overlay function was used to impute such attributes at the block-group level, in order to spatially match them to the vehicle ownership data. Table 1 provides summary statistics of all variables at the Census block-group level.

Table 1. Summary Statistics of Model Variables at the Zone Level

\begin{tabular}{|c|c|c|c|c|c|}
\hline & Mean & Median & Std. Dev. & Min & Max \\
\hline $\begin{array}{c}\text { Number (\#) of Households } \\
\text { (\#HHs) }\end{array}$ & 513.2 & 455.7 & 277.5 & 0 & $2.494 \mathrm{E}+03$ \\
\hline $\begin{array}{c}\text { Resident Worker Density } \\
\text { (\# per acre) }\end{array}$ & 8.899 & 5.561 & 10.90 & 0 & 208.1 \\
\hline $\begin{array}{c}\text { Emp. Density } \\
\text { (jobs per acre) }\end{array}$ & 9.651 & 2.727 & 51.03 & $1.500 \mathrm{E}-05$ & 1124.8 \\
\hline Pop. Density & 21.34 & 12.722 & 25.03 & 0 & 360.2 \\
\hline
\end{tabular}

\footnotetext{
${ }^{2}$ The term "resident workers" refers to those who list themselves as employed (either full or part time) and reside in the zone. Such individuals typically work outside the zone in question.
} 


\begin{tabular}{|c|c|c|c|c|c|}
\hline (persons per acre) & & & & & \\
\hline $\begin{array}{c}\text { Income> \$35K Density } \\
\text { (\# of households with incomes } \\
\text { over \$35,000 per year, per acre) }\end{array}$ & 4.08 & 2.599 & 5.578 & 0 & 147.7 \\
\hline $\begin{array}{c}\text { Centerline Density (centerline } \\
\text { miles of roadway per square } \\
\text { mile of zone area) }\end{array}$ & $5.087 \mathrm{E}+04$ & $1.521 \mathrm{E}+04$ & $1.124 \mathrm{E}+05$ & 0 & $1.920 \mathrm{E}+06$ \\
\hline $\begin{array}{c}\text { Euclidean Distance to CBD } \\
\text { (mi.) }\end{array}$ & 12.38 & 9.111 & 9.706 & 0 & 49.67 \\
\hline HH0wrk Density (\# per acre) & 2.874 & 1.269 & 4.276 & 0 & 92.52 \\
\hline HH1wrk Density (\# per acre) & 3.216 & 1.748 & 4.772 & 0 & 122.4 \\
\hline HH2wrk Density (\# per acre) & 1.868 & 1.214 & 2.257 & 0 & 38.96 \\
\hline HH3wrk Density (\# per acre) & 0.428 & 0.262 & 0.514 & 0 & 5.449 \\
\hline Response Variables (Counts) & & & & 1 & 14,697 \\
\hline ICEVs & 736.9 & 598.0 & 558.0 & 1 & 19 \\
\hline Non-Prius EVs & 1.749 & 1 & 2.333 & 0 & 37 \\
\hline Prius EVs & 4.474 & 2 & 5.773 & 0 & 0 \\
\hline
\end{tabular}

1

After merging the demographic and employment count information from the DVRPC with the vehicle count layer (originally provided by the Delaware Valley Regional Planning Commission), there were 2,909 Census block groups with both the response variables (vehicle counts by type) and explanatory variables available.

According to planners at the DVRPC, $\$ 35,000$ is an important household income threshold that is specially tracked, in part due to distinct travel patterns; thus, the density of these households was tested as a covariate. Densities for most variables were used here because the vehicleownership rate per zone is scaled by the number of households per zone. In other words, the negative binomial process modeled here (described in detail below) benefits from an exposure or size term, which here is the number of households (or population) per zone. (In theory, if the number of households or persons doubles, one expects the number of owned vehicles to double, ceteris paribus, in each of the three categories modeled. As is common in the practice of countmodel estimation, this work allows for a non-unitary parameter on the natural logarithm of households per zone, in order to provide more flexibility than forcing the model to exactly scale.)

Network connectivity may also have a bearing on vehicle ownership. For example, abundance of roadway resources invites more vehicular travel, indirectly increasing household vehicle ownership. And poorly-connected networks can stymie direct travel while increasing congestion, possibly incentivizing the purchase of more fuel-efficient vehicles (including EVs). In this model, network features are proxied by the centerline-mile density of primary and secondary roads ${ }^{3}$.

\footnotetext{
${ }^{3}$ Primary and secondary roadway networks were obtained from the 2011 Census Tiger/Line archive for the state of Pennsylvania, at http://catalog.data.gov/dataset/tiger-line-shapefile-2012-series-information-file-for-the-primaryand-secondary-roads-state-bas Primary roads essentially refer to freeways and expressways and other divided, limited-access highways that are state-maintained or part of the interstate highway system. Secondary roads are major arterial streets, with multiple lanes of traffic in each direction, at-grade intersections, and possibly undivided medians.
} 
Centerline density (for primary and secondary roads) was computed as the ratio between miles of roadway and area of block groups (in square miles).

The population and jobs data were used in map format to define the regional CBD. Both densities spike in the central Philadelphia area, corresponding to the rectangular area shown in Figure 1. For block groups within this rectangular (CBD) area, the distance-to-CBD values were set to zero; for block groups outside of this zone, Euclidean distances from each block group's centroid were computed, to the centroid of the CBD rectangle.

\section{METHODOLOGY}

Zone-level vehicle-ownership counts, by type of vehicle, can be modeled as a spatial count context with a multivariate response vector (of size $3 \times 1$ here), such as the model proposed and estimated by Wang and Kockelman (2013). Wang and Kockelman's (2013) new specification allows for multiple, simultaneous integer count responses, as well as spatial autocorrelation (due to missing variables that trend in space), zonal heterogeneity, and spatially-lagged ${ }^{4}$ and aspatial cross-correlations (across counts). A three-level response model is specified here, with the first stage (for vehicle count values) expressed as a Poisson process:

$$
y_{i k} \sim \operatorname{Poisson}\left(\lambda_{i k}\right)
$$

where $y_{i k}$ is the observed vehicle count by type ( $k=1$ denotes Prius EVs, 2 denotes non-Prius EVs, and 3 denotes ICEVs) for the $i^{\text {th }}$ block-group polygon of the five-county Delaware Valley region. The (non-negative) average crash rates for each zone and vehicle type, $\lambda_{i k}$, are defined in the second stage, as follows:

$$
\lambda_{i k}=E_{i}^{\alpha} \cdot \exp \left(x_{i}^{\prime} \beta_{k}+\phi_{k}+u_{i}\right)
$$

where $E_{i}^{\alpha}$ is the exposure or scaling term, of household population (per zone), as discussed earlier. The vector of all spatial random terms $\boldsymbol{\phi}=\left(\boldsymbol{\phi}_{1}^{\prime}{ }_{1}, \boldsymbol{\phi}_{2}^{\prime}, \boldsymbol{\phi}_{3}^{\prime}\right)^{\prime}$ is multivariate normally distributed, where $\phi_{\mathrm{k}}$ is an $n$ by 1 vector of spatial random effects or errors for ownership rates of the type $k$ vehicle, such that:

$$
\left(\begin{array}{l}
\boldsymbol{\phi}_{1} \\
\boldsymbol{\phi}_{2} \\
\boldsymbol{\phi}_{3}
\end{array}\right) \sim N\left(\left(\begin{array}{l}
\boldsymbol{\mu}_{1} \\
\boldsymbol{\mu}_{2} \\
\boldsymbol{\mu}_{3}
\end{array}\right),\left[\begin{array}{ccc}
\Sigma_{11} & \Sigma_{12} & \Sigma_{13} \\
\Sigma_{12}^{\prime} & \Sigma_{22} & \Sigma_{23} \\
\Sigma_{13}^{\prime} & \Sigma_{23}^{\prime} & \Sigma_{33}
\end{array}\right]\right)
$$

where the $n$ by 1 vector $\boldsymbol{\mu}_{\mathrm{k}}$ indicates the average ownership rate for response/vehicle type $k$ ( $k=$ $1,2,3)$, and $\Sigma_{k l}$ are $n$ by $n$ matrices describing the covariance structure between response types $k$ and $l$.

\footnotetext{
4 "Spatially-lagged cross-correlation" captures the correlation across different vehicle types that occurs across space (mathematically expressed by the component $\eta_{1} W$ in matrix A), while aspatial correlation describes the standard correlation (like that in an aspatial multivariate count model) across different response types, as formulated by the remaining component, $\eta_{0} I$ in matrix A.
} 
1 The three-level scheme developed here decomposes the massive covariance structure into a 2 series of conditional distributions that allow for spatial autocorrelation (measured by parameters

$3 \rho_{1}, \rho_{2}$, and $\rho_{3}$ ), aspatial cross-correlations (gauged by parameters $\eta_{0,23}, \eta_{0,13}$, and $\eta_{0,12}$ ), and 4 spatially-lagged cross-correlations (expressed by parameters $\eta_{1,23}, \eta_{1,13}$, and $\eta_{1,12}$ ). Details about 5 model specification are provided in the Appendix.

This three-level multivariate conditional autoregressive (MCAR) model structure was thus used to simultaneously predict counts of registered Toyota Prius EVs, non-Prius EVs (all EVs

9 excluding the Prius), and ICEVs for the Philadelphia region. The parameters were estimated 10 using Bayesian Markov-chain Monte Carlo sampling techniques, coded in R and WinBUGS, as 11 described in Wang and Kockelman (2013). Due to computing limitations with larger sample 12 sizes (from non-standard posterior likelihoods [i.e., likelihood functions that do not follow a 13 known distributional form] associated with discrete count process and complex covariance 14 structures), Table 2's parameter estimates come from an $n=1,000$ block-group sub-sample for 15 central Philadelphia, rather than the original 2,909 block groups that exist across the wider 16 region (and have complete data, as discussed earlier). Figure 1 shows the spatial distribution of 17 these vehicle counts (per household). 

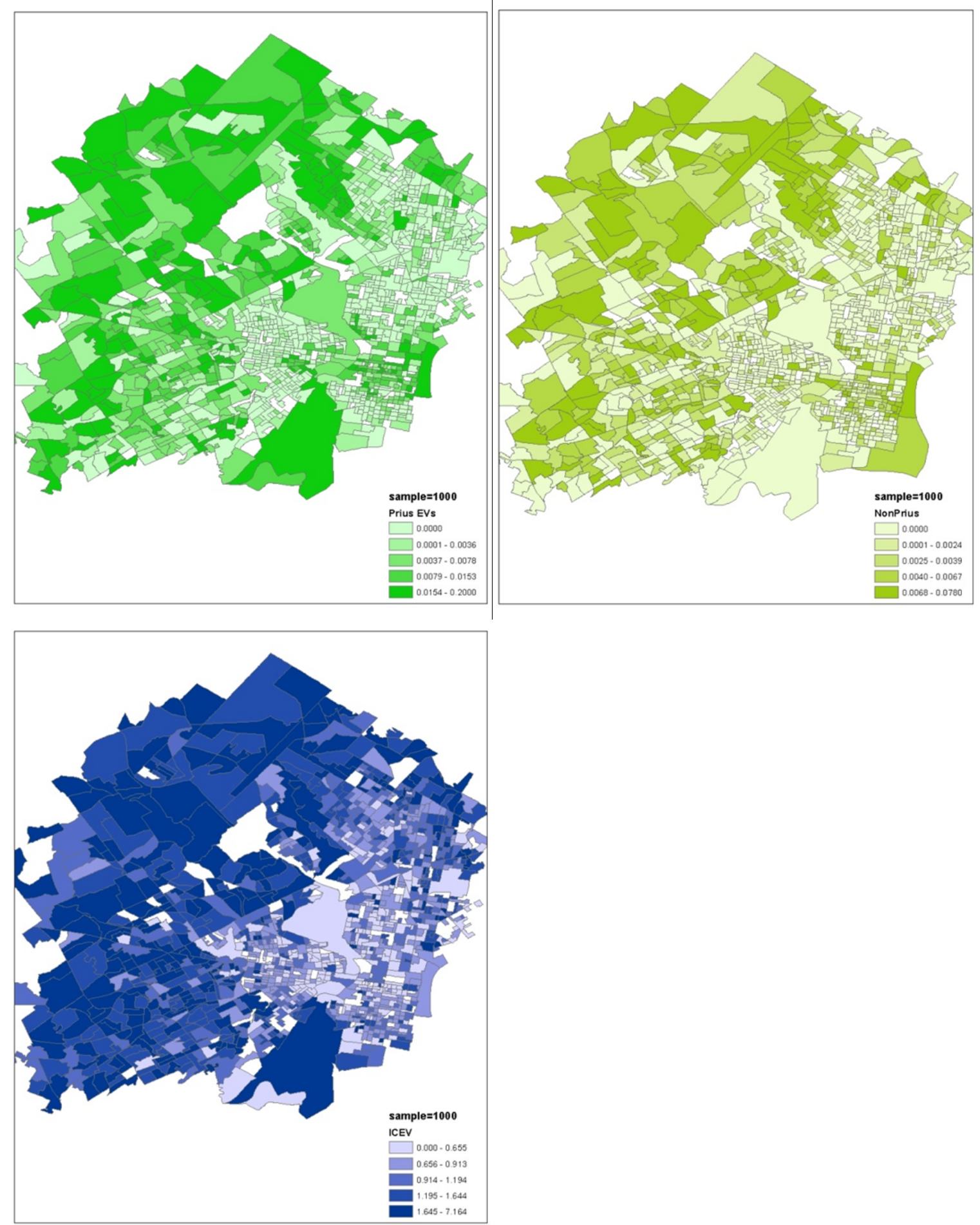

Figure 1. Locations of Vehicle Counts (by Type) per Household across Philadelphia Zones (Clockwise: Prius EVs, non-Prius EVs, and ICEVs) 


\section{RESULTS}

As shown in Table 2, several control variables are associated with higher levels of vehicle ownership, per household (in the block group) -- regardless of vehicle type. For example, resident worker density is associated with more vehicles of each type, as expected, since most American workers drive alone to work (McKenzie et al. 2010)). Elasticities ${ }^{5}$ suggest that for a one-percentage point increase in resident-worker density (a measure of local population density), average increases of 3.4, 3.7, and 5.1 percentage points are expected in Prius EV, non-Prius EV, and ICEV ownership rates (vehicles per households) across zones, respectively. Zonal household counts (serving as the size measure in its logarithmic form) and employment density are also positively correlated with greater vehicle counts in a zone, with fairly strong statistical and practical significance. Population density is not practically significant here, for EV ownership levels, once household counts and resident-worker densities are accounted for, perhaps due to this variable being inflated by household members who do not drive (such as young children and the disabled or very elderly). However, this term exhibits a strong marginal effect on ICEV ownership rates, with an elasticity estimate of +2.7 percent, suggesting the higher likelihood of larger-vehicle ownership rates for households with such non-drivers (e.g., Brownstone and Fang [2009] estimated higher rates of pickup-truck ownership in California). Indeed, as of model year (MY) 2012, the only EVs offering seating capacity above five were the Toyota Highlander HEV and the Chevrolet Tahoe/GMC Yukon/Cadillac Escalade HEVs (with the latter three vehicles all built on the same platform). In the current car market, larger families who require more passenger and cargo capacities simply have fewer choices, when seeking an EV versus an ICEV.

Not surprisingly, higher shares of households with annual incomes above $\$ 35,000$ are associated with higher vehicle ownership rates of all three types. In contrast, a higher density of lowerincome households (those with less than $\$ 35,000$ annual income) is negatively associated with EV ownership rates, though positively associated with ICEV ownership rates. The price premiums on new EVs as compared to their ICEV counterparts range from $\$ 2,655$ to $\$ 6,160$, for MY 2012 vehicles (Cunningham 2012) and no doubt pose a barrier for lower income families when considering EVs (despite the value of EVs' longer term fuel-cost savings, as computed in Khan and Kockelman [2012] and Tuttle and Kockelman [2012]). Low EV ownership rates among lower income households may also be attributed to the limited selection of used EVs in the market, as compared to used ICEVs. Interestingly, more ownership of non-Prius EVs is expected (with a highly elastic average zone-based elasticity of $+2.6 \%$ ) when the density of households having over $\$ 35,000$ annual income increases by one percent, versus ownership of Prius EVs (with an elasticity of just $+0.8 \%$ ). This finding may reflect the Prius' relative modest price among all EVs as well as its longer history on the market compared to other EVs (thus making more Priuses available on the used vehicle market).

Controlling for all other variables, greater distance to the regional CBD is associated with much lower ownership of both EV types $(k=1,2)$ and higher ICEV ownership: A one-percent increase in distance to CBD is accompanied by an average $2.3 \%$ increase in ICEV ownership rates as well

\footnotetext{
${ }^{5}$ Here, elasticities represent the median value of the (MCMC-based) distribution of the averaged percentage increase in vehicle ownership rates (averaged across the 1000 zones in the sample) following a one-percent increase in each covariate (across all sampled zones), holding all other covariate values (in the sample) constant.
} 
as a $26.2 \%$ and $20 \%$ decrease, respectively, in Prius EV, non-Prius EV ownership rates at the block group level. These results are highly elastic, suggesting that the CBD distance variable is proxying for a variety of relevant attributes that change with distance but were not available as covariates here, such as parking prices and parking space availability (which track land values, mostly), transit access, and so forth. The fuel economy (Michalek et al. 2011) and vehicle size benefits of EVs, coupled with range anxiety for households living further from the regional center, may also be at play, in this ownership vs. distance relationship. The parameter coefficients of the $\ln (\# \mathrm{HHs}$ ) variable (i.e., the natural logarithm of household counts per zone) across the three models were estimated to be $0.75,0.8$, and 0.67 for Prius EV, non-Prius EV, and ICEV counts, respectively, which suggests fewer vehicles per household in zones with more households (which may be due to more population-dense zones having more households, even though population density was also controlled for here [in a linear way]).

Centerline-mile density appears to have no influence on ownership rates, ceteris paribus. Zeroworker households are negatively associated with vehicle ownership rates across all types, presumably due to lower travel needs and lower incomes. Negative association is also found between the density of households with $3+$ workers and EV ownership rates (with elasticities of $0.6 \%$ and $-2.6 \%$, respectively) and a positive correlation with ICEV ownership rates $(+3.0 \%$ elasticity). Higher jobs densities come with substantially higher average vehicle counts across all types: the effects are very elastic, with values of $2.5 \%, 3.0 \%$ and $6.9 \%$, for Prius-EVs, non-Prius EVs, and ICEVs, respectively.

Seemingly random variations in all three vehicle ownership rates exhibit spatially clustering, as measured by the autocorrelation coefficients $\rho_{1}, \rho_{2}$ and $\rho_{3}$. By model construction, these spatial effects capture missing variables that trend in space, such as parking prices, congestion, and land use intensity, which affect vehicle ownership decisions. The remarkably high (aspatial) correlation between non-Prius EV and Prius EV error terms (described via the parameter $\eta_{012}$, with mean estimate +0.813 ) reveals that higher Prius EV counts are likely to co-exist with higher non-Prius EV counts, as expected. However, their spatial correlation (gauged by the parameter $\eta_{112}$ ) is practically insignificant (i.e., neighboring zones' Prius-EV counts have no bearing on a zone's non-Prius EV counts). In other words, the cross-correlations among different vehicle types are local (within a zone), after controlling for spatial autocorrelation across zones (from missing variables).

ICEV ownership rates exhibit a modest aspatial correlation with Prius and non-Prius EV ownership rates, as reflected by the parameters $\eta_{013}=+0.334$ (pseudo t-stat. $=1.689$ ) and $\eta_{023}=$ +0.269 (pseudo t-stat. $=1.407$ ), respectively. In other words, higher ICEV ownership rates tend to rise with EV ownership rates, which may come from underlying factors shared across all ownership rate decisions, and not captured by the model's covariates (e.g., other demographic factors and parking availability).

Interestingly, ICEVs show a rather weak spatially-lagged cross-correlation with the two EV categories $\left(\eta_{113}=+0.073\right.$ and $\left.\eta_{123}=+0.058\right)$. Using measures of spatial correlation, the results in this paper support previous findings (using non-spatial models and arguments) that vehicle technology adoption is often influenced via a "neighbor effect," where new technologies become 
1 more desirable as market penetration increases nearby (see, e.g. Mau et al. [2008] and Axen et al.

2 [2009]).

3

Table 2. Parameter Estimates for the Zone-Level Vehicle Registration Model

\begin{tabular}{|c|c|c|c|c|c|c|c|c|}
\hline & & Mean & $\begin{array}{l}\text { Std. } \\
\text { Dev. }\end{array}$ & $\begin{array}{c}\text { Pseudo } \\
\text { t-stat }\end{array}$ & $2.5 \%$ & Median & $97.5 \%$ & Elasticity \\
\hline \multirow{3}{*}{ Constant } & $\begin{array}{c}1 \\
\text { (PriusEV) }\end{array}$ & -2.138 & 0.425 & -5.037 & -2.895 & -2.105 & -1.333 & - \\
\hline & $\begin{array}{c}2 \text { (Non- } \\
\text { PriusEV) }\end{array}$ & -2.033 & 0.209 & -9.709 & -2.423 & -2.030 & -1.625 & - \\
\hline & 3 (ICEV) & 2.628 & 0.235 & 11.188 & 2.277 & 2.571 & 3.153 & 0.030 \\
\hline \multirow{3}{*}{$\begin{array}{l}\text { Resi. Worker } \\
\text { Density } \\
\text { (\# per acre) }\end{array}$} & 1 & 0.447 & 0.062 & 7.263 & 0.331 & 0.437 & 0.587 & 0.034 \\
\hline & 2 & 0.303 & 0.058 & 5.236 & 0.202 & 0.323 & 0.382 & 0.037 \\
\hline & 3 & 0.136 & 0.056 & 2.438 & 0.010 & 0.136 & 0.222 & 0.051 \\
\hline \multirow{3}{*}{$\ln (\# \mathrm{HHs})$} & 1 & 0.753 & 0.069 & 10.963 & 0.616 & 0.751 & 0.888 & 0.031 \\
\hline & 2 & 0.801 & 0.038 & 21.214 & 0.729 & 0.796 & 0.874 & 0.019 \\
\hline & 3 & 0.668 & 0.038 & 17.797 & 0.579 & 0.674 & 0.728 & 0.027 \\
\hline \multirow{3}{*}{$\begin{array}{c}\text { Emp. } \\
\text { Density. } \\
\text { (\# per acre) }\end{array}$} & 1 & 0.020 & 0.007 & 3.080 & 0.007 & 0.020 & 0.033 & 0.025 \\
\hline & 2 & 0.017 & 0.006 & 2.876 & 0.006 & 0.017 & 0.029 & 0.030 \\
\hline & 3 & 0.003 & 0.003 & 1.049 & -0.003 & 0.003 & 0.008 & 0.069 \\
\hline \multirow{3}{*}{$\begin{array}{l}\text { Pop. Density } \\
\text { (\# per acre) }\end{array}$} & 1 & -0.027 & 0.043 & -0.624 & -0.143 & -0.017 & 0.035 & -0.004 \\
\hline & 2 & -0.058 & 0.018 & -3.168 & -0.095 & -0.054 & -0.028 & 0.004 \\
\hline & 3 & 0.010 & 0.015 & 0.666 & -0.017 & 0.009 & 0.040 & 0.027 \\
\hline \multirow{3}{*}{$\begin{array}{c}\mathrm{HH}>\$ 35 \mathrm{~K} \\
\text { Density } \\
(\# \text { per acre })\end{array}$} & 1 & 1.615 & 0.146 & 11.054 & 1.383 & 1.592 & 1.864 & 0.008 \\
\hline & 2 & 1.446 & 0.148 & 9.770 & 1.191 & 1.476 & 1.694 & 0.026 \\
\hline & 3 & 0.194 & 0.084 & 2.303 & 0.052 & 0.204 & 0.327 & 0.027 \\
\hline \multirow{3}{*}{$\begin{array}{c}\mathrm{HH}<\$ 35 \mathrm{~K} \\
\text { Density } \\
(\# \text { per acre })\end{array}$} & 1 & -1.294 & 0.257 & -5.035 & -3.114 & -1.294 & -0.121 & -0.008 \\
\hline & 2 & -0.725 & 0.143 & -5.065 & -2.235 & 7.122 & -5.188 & -0.026 \\
\hline & 3 & 1.239 & 0.063 & 19.61 & 2.214 & 1.239 & 0.128 & 0.027 \\
\hline \multirow{3}{*}{$\begin{array}{c}\text { Centerline } \\
\text { Density } \\
(1 / \mathrm{mi} .) \\
\end{array}$} & 1 & -0.726 & 0.522 & -1.390 & -1.775 & -0.726 & 0.275 & 0.008 \\
\hline & 2 & -0.712 & 0.484 & -1.472 & -1.668 & -0.708 & 0.231 & -0.026 \\
\hline & 3 & -0.093 & 0.291 & -0.319 & -0.666 & -0.088 & 0.447 & -0.321 \\
\hline \multirow{3}{*}{$\begin{array}{l}\text { Dist. CBD } \\
\text { (mi) }\end{array}$} & 1 & -0.029 & 0.008 & -3.734 & -0.044 & -0.029 & -0.014 & -0.262 \\
\hline & 2 & -0.029 & 0.007 & -3.856 & -0.041 & -0.030 & -0.012 & -0.200 \\
\hline & 3 & 0.003 & 0.005 & 0.556 & -0.007 & 0.003 & 0.012 & 0.023 \\
\hline \multirow{3}{*}{$\begin{array}{c}\text { HH0wrk } \\
\text { Density } \\
\text { (\# per acre) }\end{array}$} & 1 & -0.713 & 0.110 & -6.507 & -0.902 & -0.724 & -0.485 & 0.005 \\
\hline & 2 & -0.575 & 0.091 & -6.294 & -0.748 & -0.572 & -0.397 & -0.026 \\
\hline & 3 & -0.241 & 0.051 & -4.752 & -0.341 & -0.241 & -0.143 & 0.026 \\
\hline \multirow{3}{*}{$\begin{array}{c}\text { HH1wrk } \\
\text { Density } \\
\text { (\# per acre) }\end{array}$} & 1 & -1.473 & 0.087 & -16.883 & -1.659 & -1.460 & -1.308 & 0.008 \\
\hline & 2 & -1.194 & 0.095 & -12.504 & -1.361 & -1.203 & -0.997 & -0.026 \\
\hline & 3 & -0.306 & 0.096 & -3.178 & -0.487 & -0.295 & -0.155 & -0.023 \\
\hline HH2wrk & 1 & -2.458 & 0.142 & -17.347 & -2.738 & -2.445 & -2.180 & -0.005 \\
\hline
\end{tabular}




\begin{tabular}{|c|c|c|c|c|c|c|c|c|}
\multirow{2}{*}{$\begin{array}{c}\text { Density } \\
\text { (\# per acre) }\end{array}$} & 2 & -1.809 & 0.156 & -11.633 & -2.121 & -1.800 & -1.526 & $\mathbf{- 0 . 0 2 7}$ \\
\hline \multirow{2}{*}{$\begin{array}{c}\text { HH>3wrk } \\
\text { Density } \\
\text { (\# per acre) }\end{array}$} & 3 & -0.492 & 0.161 & -3.051 & -0.851 & -0.464 & -0.242 & $\mathbf{- 0 . 0 2 5}$ \\
\hline & 2 & -3.241 & 0.369 & -8.776 & -3.905 & -3.228 & -2.504 & -0.006 \\
\hline$\eta_{012}$ & -2.571 & 0.421 & -6.103 & -3.456 & -2.505 & -1.772 & $\mathbf{- 0 . 0 2 6}$ \\
\hline$\eta_{013}$ & -0.323 & 0.353 & -0.916 & -0.966 & -0.283 & 0.302 & $\mathbf{0 . 0 3 0}$ \\
\hline$\eta_{023}$ & 0.813 & 0.056 & 14.524 & 0.694 & 0.815 & 0.911 & - \\
\hline$\eta_{112}$ & 0.334 & 0.198 & 1.689 & 0.124 & 0.252 & 0.745 & - \\
\hline$\eta_{113}$ & 0.269 & 0.191 & 1.407 & 0.076 & 0.194 & 0.702 & - \\
\hline$\eta_{123}$ & 0.074 & 0.025 & 2.932 & 0.034 & 0.071 & 0.132 & - \\
\hline$\rho_{1}$ & 0.073 & 0.025 & 2.919 & 0.032 & 0.070 & 0.129 & - \\
\hline$\rho_{2}$ & 0.058 & 0.072 & 0.810 & 0.012 & 0.026 & 0.268 & - \\
\hline$\rho_{3}$ & 0.655 & 0.108 & 6.078 & 0.429 & 0.662 & 0.844 & - \\
\hline$\tau_{\mathrm{v} 1}$ & 0.491 & 0.102 & 4.831 & 0.293 & 0.492 & 0.687 & - \\
\hline$\tau_{\mathrm{v} 2}$ & 0.913 & 0.147 & 6.217 & 0.471 & 0.974 & 0.992 & - \\
\hline$\tau_{\mathrm{v} 3}$ & 4.982 & 0.753 & 6.616 & 3.640 & 4.931 & 6.566 & - \\
\hline$\tau_{1}$ & 5.628 & 0.784 & 7.178 & 4.234 & 5.591 & 7.284 & - \\
\hline$\tau_{2}$ & 1.056 & 0.228 & 4.632 & 0.704 & 1.022 & 1.604 & - \\
\hline$\tau_{3}$ & 1.070 & 1.758 & 0.609 & 0.059 & 0.170 & 5.609 & - \\
\hline
\end{tabular}

1 Note: Bolded elasticities are practically significant, suggesting more than $1 \%$ change in the expected vehicle

\section{CONCLUSIONS}

Using a trivariate Poisson-lognormal CAR model, this study forecast registered-vehicle counts across southeastern Pennsylvania to examine the effect of zone-level characteristics on vehicle ownership rates (per resident household) of Prius EVs, non-Prius EVs, and ICEVs while reflecting spatial autocorrelation. Results reveal that all three vehicle ownership rates rise with household counts (per zone) and resident-worker densities. In particular, EV ownership is predicted to rise with as households get closer to the $\mathrm{CBD}$, perhaps due to the relatively small size of most EVs, the diminished range anxiety issues (thanks to shorter trips), and desire for greater fuel economy (in congested central-city driving conditions). The spatial clustering effects identified in this study also point to the existence of missing variables that trend in space and possibly a "neighbor effect" (from nearby households owning such vehicles). As a technology becomes more prevalent, familiarity and perceived value of such technologies and products tends to rise. The spatial autocorrelation exhibited by the results here suggest that EV purchase rates will rise, via such familiarity, thanks to rising market penetration.

The results of this study underscore the high continuing demand for ICEVs, thanks in part to the far larger choice set of vehicles in that class, versus the mostly smaller vehicles offered in the EV classes to date. (ICEs presently offer greater passenger and cargo capacity.) In general, lower income households are less likely to purchase EVs; but, when they do, they are more likely to purchase Toyota Priuses (the EV model with the longest market history) than non-Prius EVs, 
suggesting that vehicle affordability and familiarity, along with used-vehicle availability, may also be influencing EV purchase decisions.

A household's decision to purchase an EV is also influenced by many relatively complex residential and transportation characteristics, not included in this study's set of covariates. These include such things as availability of designated parking for a home charger to be installed, nearby public charging infrastructure, and commute distances (versus AER, in the case of BEVs). Nevertheless, the model presented here addresses important gaps in current research in terms of the scale of observational units (neighborhoods or zones, instead of individual households or entire regions), while reflecting spatial autocorrelation patterns, without which the estimated parameters may be biased. This model structure offers a solid framework for spatially-based choice behavior, as EV market shares rise over time, and data sets on EV ownership and infrastructure become more detailed.

\section{ACKNOWLEDGEMENTS}

The authors are grateful to Robert Graff, Mary Bell, and Chris Pollard of the DVRPC for providing this unique and useful data set, Dave Tuttle of UT Austin for alerts on EV research, and Annette Perrone for administrative support.

\section{APPENDIX}

The three-level scheme relies on a series of conditional distributions, starting from the marginal distribution of $\boldsymbol{\phi}_{3}$ which follows a multivariate normal distribution: $p\left(\boldsymbol{\phi}_{3}\right) \sim \boldsymbol{N}\left(\boldsymbol{\mu}_{3}, \Sigma_{33}\right)$, with $\boldsymbol{\mu}_{3}=\mathbf{0}$ and $\boldsymbol{\Sigma}_{33}=\left[\tau_{3}\left(\mathbf{D}-\rho_{3} \mathbf{W}\right)\right]^{-1}$. The diagonal matrix, $\mathbf{D}$, stores the number of neighbors for each geographic unit along its diagonal line; $\tau_{3}$ is a scaling factor to fine-tune the covariance matrix, $\boldsymbol{\Sigma}_{33} ; \rho_{3}$ measures the strength of spatial autocorrelation of the response type 3 (i.e., ICEVs); and the square weight matrix, $\mathbf{W}$, is defined by contiguity (i.e., $\mathbf{W}_{i j}=1$ if $i$ and $j$ share a border and $\mathbf{W}_{i j}=0$ if otherwise). For ease of exposition, one can assume the following sequence of conditional normal distributions: $p(\boldsymbol{\phi})=p\left(\boldsymbol{\phi}_{1} \mid \boldsymbol{\phi}_{2}, \boldsymbol{\phi}_{3}\right) \cdot p\left(\boldsymbol{\phi}_{2} \mid \boldsymbol{\phi}_{3}\right) \cdot p\left(\boldsymbol{\phi}_{3}\right)$. Moreover, the marginal distribution of $\left(\phi_{2}, \phi_{3}\right)$ can be obtained by removing irrelevant elements (with respect to $\phi_{2}$ and $\phi_{3}$ ) from the full distribution, leading to the following distribution:

$$
\left(\begin{array}{l}
\boldsymbol{\phi}_{2} \\
\boldsymbol{\phi}_{3}
\end{array}\right) \sim N\left(\left(\begin{array}{l}
\boldsymbol{\mu}_{2} \\
\boldsymbol{\mu}_{3}
\end{array}\right),\left[\begin{array}{ll}
\Sigma_{22} & \Sigma_{23} \\
\Sigma^{\prime} & \Sigma_{33}
\end{array}\right]\right) .
$$

Conditionally, $\boldsymbol{\phi}_{2} \mid \boldsymbol{\phi}_{3} \sim N\left(\mathbf{A}_{23} \boldsymbol{\phi}_{3},\left[\left(\mathbf{D}-\rho_{2} \mathbf{W}\right) \tau_{2}\right]^{-1}\right)$ (see Wang and Kockelman [2013]) where $\mathbf{A}_{23}$ describes the aspatial correlation between response types 2 and 3 , as well as the spatiallylagged correlation between the two response types, formally: $\mathbf{A}_{23}=\eta_{0,23} \boldsymbol{I}+\eta_{1,23} \mathbf{W}$.

Taking this conditioning one step further, $\boldsymbol{\phi}_{1} \mid \boldsymbol{\phi}_{2}, \boldsymbol{\phi}_{3} \sim N\left(\mathbf{A}_{13} \boldsymbol{\phi}_{3}+\mathbf{A}_{12} \boldsymbol{\phi}_{2}\right.$, $\left.\left[\left(\mathbf{D}-\rho_{1} \mathbf{W}\right) \tau_{1}\right]^{-1}\right)$, where $\mathbf{A}_{13}$ and $\mathbf{A}_{12}$ capture the aspatial and spatially-lagged correlation across response types 1 and 3, and response types 1 and 2, formally: $\mathbf{A}_{13}=\eta_{0,13} \boldsymbol{I}+\eta_{1,13} \mathbf{W}$ and $\mathbf{A}_{12}=\eta_{0,12} \boldsymbol{I}+\eta_{1,12} \mathbf{W}$. 


\section{REFERENCES}

2 Axsen, J., Mountain, D.C., and Jaccard, M. (2009). Combining Stated and Revealed Choice

3 Research to Simulate the Neighbor Effect: The Case of Hybrid-Electric Vehicles. Resource and

4 Energy Economics 31: 221-238.

5 Bartlett, J. (2012). Survey: Consumers Express Concerns About Electric, Plug-In Hybrid Cars.

6 Consumer Reports, January 30.

7 Bhat, C.R., Sen, S., and Eluru, N. (2009). The Impact of Demographics, Built Environment

8 Attributes, Vehicle Characteristics, and Gasoline Prices on Household Vehicle Holdings and Use.

9 Transportation Research Part B 43 (1): 1-18.

10 Brownstone, D., Bunch, D.S., Golob, T.F., and Ren, W. (1996). A Transactions Choice Model

11 for Forecasting Demand for Alternative-Fuel Vehicles. Research in Transportation Economics 4, $12 \quad 87-129$.

13 Brownstone, D. and Fang, H. (2009). Vehicle Ownership and Utilization Choice Model with 14 Endogenous Residential Density. Presented at the $88^{\text {th }}$ Annual Meeting of the Transportation 15 Research Board, Washington DC.

16 Brownstone, D. and Golob, T.F. (2009). The Impact of Residential Density on Vehicle Usage 17 and Energy Consumption. Journal of Urban Economics 65(1): 91-98.

18 Clement-Nyns, K, Haesen, E., and Driesen J. (2010). The Impact of Charging Plug-In Hybrid

19 Electric Vehicles on a Residential Distribution Grid. IEEE Transactions on Power Systems 20 25(1): 371-380.

21 Cunningham, W. (2012). The Hybrid Premium: How Much More Does a Hybrid Car Cost?

22 CNET Car Tech Blog, April 30. Retrieved from http://reviews.cnet.com/8301-13746 7-

23 57424518-48/the-hybrid-premium-how-much-more-does-a-hybrid-car-cost/

24 EIA (2013). Annual Energy Outlook 2011. U.S. Energy Information Agency. Retrieved from

25 http://www.eia.gov/forecasts/aeo/

26 Erdem, C., Senturk, I., Simsek, T. (2010). Identifying the Factors Affecting the Willingness to

27 Pay for Fuel-Efficient Vehicles in Turkey: A Case of Hybrids. Energy Policy (3) 8: 3038-3043.

28 Fang, H. 2008. A Discrete-Continuous Model of Households" Vehicle Choice and Usage, with 29 an Application to the Effects of Residential Density. Transportation Research Part B, 42(9):

$30 \quad 736-758$.

31 Harrop, P. and Das, R. (2012) Hybrid and Pure Electric Cars 2012-2022. IDTechEX Research

32 Report, October 2012.

33 Khan, M. and Kockelman, K.M. (2012) Predicting the Market Potential of Plug-in Vehicles

34 Using Multiday GPS Data. Energy Policy 46: 225-233.

35 Khan, M., Kockelman, K., and Xiong, X. (2013) Models for Anticipating Non-Motorized Travel

36 Choices, and the Role of the Built Environment. Under review for publication in Transport

37 Policy.

38 Mau, P., Eyzaguirre, J., Jaccard, M., Collins-Dodd, C., and Tiedemann, K. (2008). The

39 'Neighbor Effect": Simulating Dynamics in Consumer Preferences for New Vehicle

40 Technologies. Ecological Economics 68: 504-516. 
McKinsey (2011). The Fast Lane to the Adoption of Electric Vehicles. McKinsey Quarterly,

2 February 2011.

4

McKenzie, B., Koerber, W., Fields, A., Benetsky, M., and Rapino, M. (2010) Commuter-

Adjusted Population Estimates: ACS 2006-10. U.S. Census Bureau. URL:

http://www.census.gov/hhes/commuting/files/ACS/Commuter\%20Adjusted\%20Population\%20P aper.pdf

Michalek, J., Chester, M., Jaramillo, P., Samaras, C., Shiau, C.S., and Lave, L.N. (2011).

Valuation of plug-in vehicle life-cycle air emissions and oil displacement benefits. Proceedings

of the National Academy of Sciences vol. 108(40), 16554-16558.

10 Neubauer, J. S., Pesaran, A., Williams, B., Ferry, M., and Eyer J. (2012) A Techno-Economic

11 Analysis of PEV Battery Second Use: Repurposed-Battery Selling Price and Commercial and

12 Industrial End-User Value. Proceedings of the 2012 SAE World Congress and Exhibition,

13 Detroit. URL: http://www.nrel.gov/vehiclesandfuels/energystorage/pdfs/53799.pdf

14 NRC (2010). Transition to Alternative Transportation Technologies - Plug-In Hybrid Electric

15 Vehicles. National Academies Press. Washington, D.C.

16 Paul, B.M., Kockelman, K.M., Musti, S. (2011). The Light-Duty-Vehicle Fleet's Evolution:

17 Anticipating PHEV Adoption and Greenhouse Gas Emissions Across the U.S. Fleet.

18 Transportation Research Record 2252: 107-117.

19 Pike Research. (2011). Electric Vehicle Geographic Forecasts.

20 Potoglou, D., and Kanaroglou, P.S. (2008). Modeling Car Ownership in Urban Areas: A Case

21 Study of Hamilton, Canada. Journal of Transport Geography, 16: 42-54.

22 Schweinberg, C. (2013, May 14). U.S. Hybrid, EV Sales Buck Truck Trend. WardsAuto.

23 Retrieved from http://wardsauto.com/sales-amp-marketing/us-hybrid-ev-sales-buck-truck-trend.

24 Smart, J., Powell, W., and Schey, S. (2013). Extended Range Electric Vehicle Driving and

25 Charging Behavior Observed Early in the EV Project. Society of Automotive Engineers (SAE)

26 Technical Paper 2013-01-1441.

27 Tate, E. D., Harpster, M.O., and Savagian, P.J. (2008) The Electrification of the Automobile:

28 From Conventional Hybrid, to Plug-in Hybrids, to Extended-Range Electric Vehicles. SAE

29 International World Congress. SAE Technical Paper 2008-01-0458.

30 Taylor, D. (2009). The Differences and Similarities Between Plug-in Hybrid EVs and Battery

31 EVs. Available at http://www.cars21.com/knowledge/papersView/97.

32 Tuttle, D. and Kockelman, K. (2012) Electrified Vehicle Technology Trends, Infrastructure

33 Implications, and Cost Comparisons. J of the Transportation Research Forum 51 (1): 35-51.

34 Wang, Y. and Kockelman, K. (2013) A Poisson-lognormal Conditional-Autoregressive Model

35 for Multivariate Spatial Analysis of Pedestrian Crash Counts across Neighborhoods.

36 Forthcoming in Accident Analysis \& Prevention.

37 Wellings, T., Binnersley, J., Robertson, D., and Khan, T. (2011). Human Machine Interfaces in

38 Low Carbon Vehicles: Market Trends and User Issues. Document No. HMI 2. Coventry: The

39 University of Warwick. Retrieved from: 
1 http://www2.warwick.ac.uk/fac/sci/wmg/research/lcvtp/news/hevc11/ws13 hmi in lcvs_market

2 analysis_and user_issues_v2 1.pdf

3 Zhao, Y. and K. M. Kockelman. (2002). Household Vehicle Ownership by Vehicle Type:

4 Application of a Multivariate Negative Binomial Model. Proceedings of the Transportation

5 Research Board's 81st Annual Meeting, Washington, DC.

6

7 LIST OF TABLES

8 TABLE 1 . Summary Statistics of Model Variables at the Zone Level

9 TABLE 2 Parameter Estimates for the Zone-Level Vehicle Registration Model

11 LIST OF FIGURES

12 FIGURE 1. Locations of Vehicle Counts (by Type) per Household across Philadelphia Zones 